\title{
PRESERVATION OF THE RIGHT ATRIAL APPENDAGE IMPROVES REDUCED PLASMA ATRIAL NATRIURETIC PEPTIDE LEVELS AFTER THE MAZE PROCEDURE
}

Fumiki Yoshihara, MD

Toshio Nishikimi, MD $^{\mathrm{a}}$

Yoshikado Sasako, $\mathrm{MD}^{\mathrm{b}}$

Junjiro Kobayashi, $\mathrm{MD}^{\mathrm{b}}$

Yoshio Kosakai, MD

Reiji Hattori, $\mathrm{MD}^{\mathrm{b}}$

Takeshi Horio, $\mathrm{MD}^{\mathrm{b}}$

Soichiro Kitamura, $\mathrm{MD}^{\mathrm{b}}$

Hisayuki Matsuo, $\mathrm{PhD}^{\mathrm{a}}$

Tohru Ohe, $\mathrm{MD}^{\mathrm{c}}$

Kenji Kangawa, $\mathrm{PhD}^{\mathrm{a}}$
Objectives: The present study was conducted to determine whether preservation of the right atrial appendage lessens the decrease of plasma atrial natriuretic peptide levels after the maze procedure and whether the increase of plasma atrial natriuretic peptides improves the ability of the kidneys to excrete the fluid load after the operation.

Methods: We evaluated 42 patients who underwent the maze procedure. The right atrial appendage was preserved in 22 patients but not in 20. Blood samples were obtained before and after the operation for measurement of atrial natriuretic peptides. To evaluate the influence of atrial natriuretic peptides on the ability of the kidneys, we also measured body weight, fluid balance, and the doses of furosemide and dopamine administered after the operation.

Results: The restoration to sinus rhythm at 1 month after was comparable in the two groups. Plasma atrial natriuretic peptide levels significantly increased after the operation in patients in whom the right atrial appendage was preserved ( 1 day after: $23.4 \pm 17.8$ vs 3 days after: $42.7 \pm 23.6$ and 7 days after: $36.3 \pm 23.7 \mathrm{pg} / \mathrm{mL}, P<.05)$ but not in patients in whom the right atrial appendage was not preserved ( 1 day after: $20.0 \pm 19.6,3$ days after: $28.5 \pm 19.3$, and 7 days after: $23.0 \pm 16.1 \mathrm{pg} / \mathrm{mL})$. Furthermore, plasma atrial natriuretic peptide levels were significantly lower in patients in whom the right atrial appendage was not preserved than in patients in whom the right atrial appendage was preserved at 3 and 7 days after the operation. The fluid balance during the first 7 days of the postoperative period was comparable in the two groups, although the total dose of dopamine used in the same period was significantly smaller in patients in whom the right atrial appendage was preserved than in patients in whom the right atrial appendage was not preserved $(155.3 \pm 119.0$ vs $244.9 \pm 129.0 \mu \mathrm{g} / \mathrm{kg}, P<.05)$.

Conclusions: The present study showed that preservation of the right atrial appendage lessens the decrease of plasma atrial natriuretic peptide levels after the maze procedure and that increased plasma atrial natriuretic peptides may improve the ability of the kidneys to excrete the fluid load after the operation. (J Thorac Cardiovasc Surg 2000;119:790-4)
T he maze procedure consists of bilateral atrial appendectomy, atriotomy, reanastomosis, and cryoablation. The maze procedure effectively restores atrial fibrillation to sinus rhythm and to atrial systole. ${ }^{1-5}$ However, the development of significant fluid retention during the early postoperative period after the maze

From the National Cardiovascular Center Research Institute, ${ }^{\text {a }}$ the Division of Cardiovascular Surgery and Hypertension, ${ }^{\mathrm{b}}$ and the Department of Cardiovascular Medicine, ${ }^{\mathrm{c}}$ Okayama University Medical School, Okayama, Japan.

Received for publication June 14, 1999; revisions requested Sept 7, 1999; revisions received Nov 19, 1999; accepted for publication Nov 23, 1999. procedure was reported by several groups. ${ }^{2,3}$ Previous studies have shown that reduced atrial natriuretic peptide (ANP) levels after the maze procedure may contribute to body fluid retention. ${ }^{6,7}$ Right atrial or bilateral atrial appendectomy in animal models eliminates the release of ANP and blunts the renal excretion of sodium

\footnotetext{
Address for reprints: Fumiki Yoshihara, MD, National Cardiovascular Center, Research Institute, 5-7-1 Fujishirodai, Suita, Osaka, 565-8565, Japan.

Copyright (C) 2000 by The American Association for Thoracic Surgery.

$0022-5223 / 2000 \$ 12.00+0 \quad \mathbf{1 2} / \mathbf{1} / \mathbf{1 0 4 5 8 1}$

doi: $10.1067 / \mathrm{mtc} .2000 .104581$
} 
and water after a large acute volume load. ${ }^{8-14}$ In a clinical study Omari and colleagues ${ }^{15}$ demonstrated that right atrial appendectomy performed during an elective coronary artery bypass operations reduced the secretion of ANP and the excretion of sodium after volume expansion. Furthermore, the concentration of ANP in the right atrial appendages of human hearts is remarkably higher than that in the remainder of the atrial free wall. ${ }^{16}$ These results suggest that atrial appendectomy may reduce the ability of the kidneys to handle the fluid load after the maze operation. In the present study, to determine whether the preservation of the right atrial appendage improves reduced plasma ANP levels after the maze procedure and whether the improvement of plasma ANP levels affect the ability of the kidneys after the operation, we measured plasma ANP levels before and after the operation in patients who underwent the maze procedure with right atrial appendectomy or without it.

\section{Methods}

Patients and surgical methods. Forty-two patients who underwent cardiac operations were studied. Each subject provided informed consent for participation. From November 1994 to June 1995, consecutive patients with atrial fibrillation as a result of organic heart disease underwent the maze procedure, the right atrial appendage was amputated before right atrial atriotomy, and cryoablation in the Kosakai maze procedure was performed as previously reported ${ }^{17}$ (group RAAX ${ }^{+}$, $\mathrm{n}=20$ ). On the other hand, from June 1998 to January 1999, consecutive patients with atrial fibrillation as a result of organic heart disease underwent the maze procedure, and the right atrial appendage was preserved (group $\mathrm{RAAX}^{-}, \mathrm{n}=22$ ). Instead of right atrial appendectomy, right atriotomy and cryoablation were extended to a tip of the right atrial appendage. Both groups were operated on by using cardiopulmonary bypass.

Protocol. Heart rate and blood pressure were measured after at least 30 minutes of supine rest. Blood was withdrawn through the antecubital vein 1 day before operation and 1, 3, 7 , and 21 days afterward. Blood was immediately transferred into chilled glass tubes containing disodium ethylenediaminetetraacetic acid $(1 \mathrm{mg} / \mathrm{mL})$ and aprotinin $(500 \mathrm{U} / \mathrm{ml})$ for measurement of plasma ANP levels. Blood was centrifuged immediately at $4^{\circ} \mathrm{C}$, and the plasma was frozen and stored at $-80^{\circ} \mathrm{C}$ until assayed.

Measurements of ANP. Radioimmunoassay was performed to measure plasma ANP levels (Shiono RIA ANP assay kit; Shionogi Co, Ltd, Osaka, Japan) as previously reported. ${ }^{18}$

Echocardiography. Echocardiographic studies were performed before and about 3 weeks after surgery. All patients were studied in the decubitus position by using the standard echocardiographic technique as previously reported. ${ }^{19,20}$ An M-mode echocardiogram was recorded with 2-dimensional monitoring by using a Hewlett-Packard 77020A phased-array ultrasound sector scanner (Hewlett-Packard Company,
Andover, Mass) or Toshiba SSH 160A echocardiographic system (Toshiba, Tokyo, Japan) with a $2.5-$ or $3.75-\mathrm{MHz}$ transducer. Standard echocardiographic variables, including left ventricular dimension in end-diastole (LVDd), end-systolic left ventricular dimensions, and left atrial dimensions, were determined according to the recommendation of the American Society of Echocardiography before and after the operation. Simultaneously, left ventricular fractional shortening (FS) was calculated by using the standard formula.

Cardiac catheterization. Right- and left-sided cardiac catheterization was performed in all patients before the operation. Cardiac output was measured by using the thermodilution method. The cardiac index was calculated by dividing the cardiac output by body surface area. Left ventriculography was performed, and the ejection fraction was calculated.

Body fluid balance. Because daily body weight has been used in fluid balance studies as an indicator of positive or negative fluid balance, we evaluated body weight changes in the two groups during the first 7 days of the postoperative period. Furosemide has traditionally been used to promote urine flow. Dopamine administration has been associated with both increased urine flow and increased sodium excretion. ${ }^{21-24}$ In addition, experimental ${ }^{25}$ and clinical ${ }^{26}$ studies have shown the synergistic diuretic effect of combined dopamine and furosemide. In this study all patients were freely administered both furosemide and dopamine during the early postoperative period by physicians to maintain negative body fluid balance. We calculated the amounts of fluids, urinary volume, and body fluid balance at each study period $(1,3$, and 7 days after surgery) and total amount of body fluid balance during the first 7 days of the postoperative period. The cumulative doses of furosemide and dopamine administered during the first 7 days of the postoperative period were also calculated to evaluate whether ANP secretion affects the ability of the kidneys to handle fluid load during these postoperative periods in both groups. Mean cardiopulmonary bypass time and aortic crossclamp time were also calculated to evaluate surgical invasion during the heart operation.

Statistics. Data are presented as means \pm SD of the mean. Comparisons between the two groups were performed by using the standard unpaired Student $t$ test or $\chi^{2}$ test. Variables obtained during early postoperative periods were tested by using analysis of variance followed by the Fisher post hoc test.

\section{Results}

The clinical characteristics of the patients are summarized in Table I. There were no significant differences between the two groups in age, sex, body surface area, left atrial dimension, ejection fraction, cardiac index, cardiopulmonary bypass time, or aortic crossclamp time. There were no significant differences between the two groups in underlying heart disease and operation. Five patients in the $\mathrm{RAAX}^{+}$group and 7 in the $\mathrm{RAAX}^{-}$group had aortic valve diseases and underwent aortic valve replacement simultaneously. There was also no significant difference between the two groups in the restoration 
Table I. Comparison of clinical characteristics of patients, underlying disease, operation, left atrial dimension, ejection fraction, cardiac index, cardiopulmonary bypass time, aortic crossclamp time, and sinus rhythm at 1 month after operation

\begin{tabular}{|c|c|c|c|}
\hline & $\begin{array}{l}R A A X^{+} \\
(n=20)\end{array}$ & $\begin{array}{l}R A A X^{-} \\
(n=22)\end{array}$ & $\mathrm{P}$ value \\
\hline Age (y) & $53.1 \pm 7.4$ & $57.2 \pm 9.4$ & .12 \\
\hline $\operatorname{Sex}(M / F)$ & $10 / 10$ & $16 / 6$ & .13 \\
\hline $\operatorname{BSA}\left(\mathrm{m}^{2}\right)$ & $1.57 \pm 0.20$ & $1.64 \pm 0.16$ & .21 \\
\hline \multicolumn{4}{|l|}{ Underlying disease } \\
\hline MS/MR/MSR & $10 / 5 / 4$ & $9 / 7 / 4$ & .84 \\
\hline VSD/ASD & $1 / 0$ & $0 / 2$ & .33 \\
\hline \multicolumn{4}{|l|}{ Operation } \\
\hline OMC/MVR/MVP & $2 / 11 / 6$ & $1 / 14 / 5$ & .68 \\
\hline VSD/ASD closure & $1 / 0$ & $0 / 2$ & .33 \\
\hline $\begin{array}{l}\mathrm{LAD}(\mathrm{mm}, \\
\text { preoperative })\end{array}$ & $55.8 \pm 9.0$ & $57.8 \pm 12.9$ & .59 \\
\hline $\mathrm{EF}$ (\%, preoperative) & $51.5 \pm 8.7$ & $47.8 \pm 13.8$ & .39 \\
\hline $\begin{array}{l}\mathrm{CI}\left(\mathrm{L} / \mathrm{min} / \mathrm{m}^{2}\right. \\
\text { preoperative })\end{array}$ & $2.6 \pm 0.8$ & $2.6 \pm 0.5$ & .86 \\
\hline CPBT (min) & $196.2 \pm 28.5$ & $201.5 \pm 49.9$ & .68 \\
\hline ACCT (min) & $128.9 \pm 23.0$ & $139.6 \pm 41.3$ & .31 \\
\hline SR at $1 \mathrm{mo}$ after & $16 / 20(80 \%)$ & $18 / 22(82 \%)$ & .96 \\
\hline
\end{tabular}

$\overline{B S A}$, Body surface area; $M S$, mitral stenosis; $M R$, mitral regurgitation; $M S R$, mitral stenosis and regurgitation; $V S D$, ventricular septal defect; $A S D$, atrial septal defect; $O M C$, open mitral commissurotomy; $M V R$, mitral valve replacement; $M V P$, mitral valvuloplasty; $L A D$, left atrial dimension; $E F$, ejection fraction; $C I$, cardiac index; $C P B T$, cardiopulmonary bypass time; $A C C T$, aortic crossclamp time.

rate to sinus rhythm at 1 month after the operation. The time courses of plasma ANP level, fluids, urinary volume, and body fluid balance during the early postoperative period are shown in Fig 1. Plasma ANP levels were significantly increased at 3 and 7 days after the operation compared with 1 day after in the $\mathrm{RAAX}^{-}$group. However, plasma ANP levels were not increased in the $\mathrm{RAAX}^{+}$group. Furthermore, plasma ANP levels at 3 and 7 days after the operation were significantly higher in the $\mathrm{RAAX}^{-}$group than in the $\mathrm{RAAX}^{+}$group. There were no significant differences in the time course of fluids, urinary volume, and body fluid balance between the two groups. The daily body weight did not significantly change in either of the groups during the early postoperative period, and there was no significant difference in the daily body weight between the two groups (Fig 2). The body fluid balance during the first 7 days of the postoperative period in the $\mathrm{RAAX}^{-}$group was also comparable with that in the $\mathrm{RAAX}^{+}$group (Fig 3, A), although the mean total dose of dopamine used in the same period was significantly smaller in the RAAX ${ }^{-}$ group than in the $\mathrm{RAAX}^{+}$group (Fig 3,C). There was no significant difference in the mean total dose of furosemide used simultaneously between the two groups (Fig 3, B). LVDd and FS measured by echocardiogram

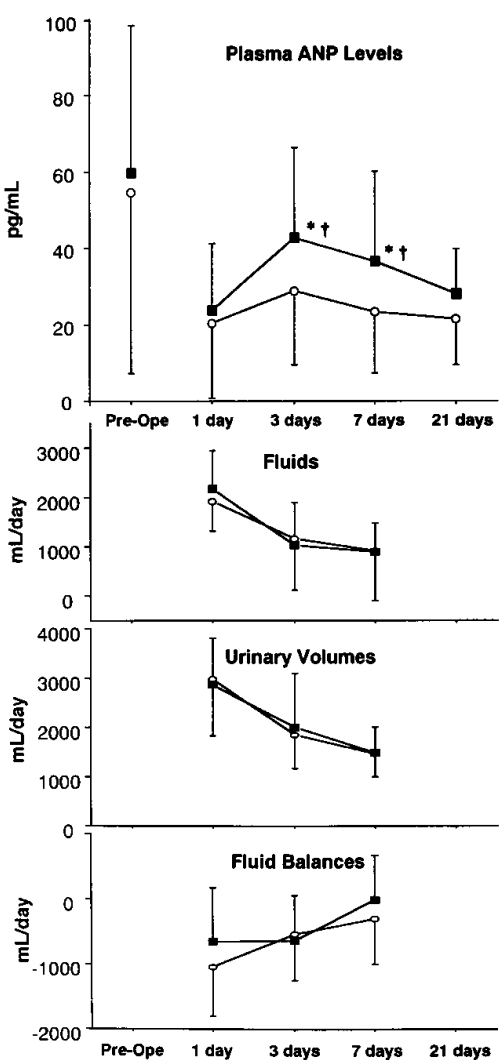

Fig 1. Time courses of changes in plasma ANP level, fluids, urinary volume, and fluid balance are shown in the RAAX ${ }^{+}$ group (open circles) and the $\mathrm{RAAX}^{-}$group (closed squares). $* P<.05$ versus 1 day; $\dagger P<.05$ versus RAAX $^{+}$group.

did not differ between groups before (LVDd: RAAX ${ }^{+}$ group $52.8 \pm 7.0 \mathrm{~mm}$ vs $\mathrm{RAAX}^{-}$group $53.0 \pm 13.2 \mathrm{~mm}$, $P=.96 ;$ FS: $32.4 \pm 8.4 \%$ vs $32.7 \pm 7.5 \%, P=.90)$ and after (LVDd: $48.0 \pm 4.9 \mathrm{~mm}$ vs $46.2 \pm 8.7 \mathrm{~mm}, P=.43$; FS: $28.6 \pm 7.7 \%$ vs $29.4 \pm 6.4 \%, P=.71$ ) the operation.

\section{Discussion}

This study demonstrated for the first time that preservation of the right atrial appendage lessens the decrease in plasma ANP levels in the early postoperative period in patients who have undergone the maze procedure. Although the cumulative dose of dopamine was significantly smaller in the $\mathrm{RAAX}^{-}$group than in the $\mathrm{RAAX}^{+}$group, the body fluid balance during the first 7 days of the postoperative period was comparable between the two groups. These results suggest that preservation of the right atrial appendage increases the reduced ANP levels after the maze procedure and that this increased ANP level may improve the ability of the kidneys to handle the fluid load after the operation.

$\mathrm{We}^{6}$ and others ${ }^{7,27}$ previously reported that plasma ANP levels were reduced after the maze procedure. 


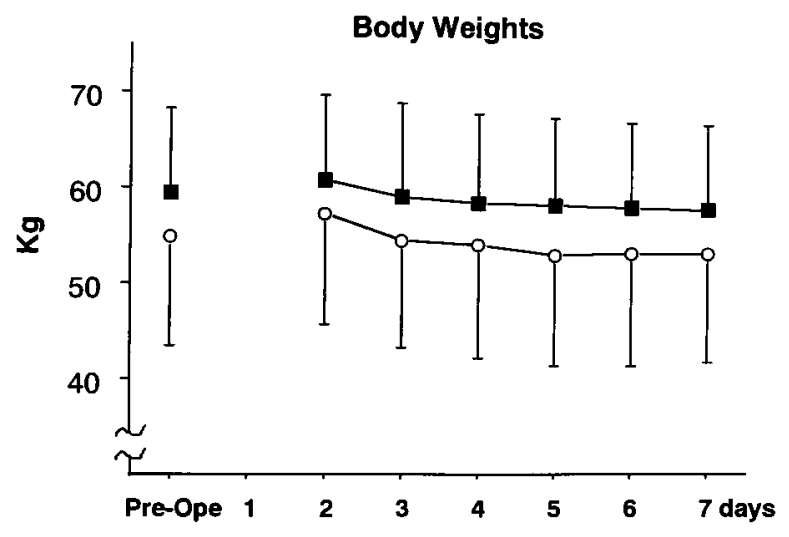

Fig 2. The daily body weights are shown in the RAAX ${ }^{+}$ group (open circles) and the $\mathrm{RAAX}^{-}$group (closed squares).

However, the mechanism responsible for the reduced plasma ANP levels after the maze procedure is still unknown. The maze procedure consists of bilateral atrial appendectomy, atriotomy, reanastomosis, and cryoablation. Because all of these methods are invasive in the atrial wall, the maze procedure may damage the atrial wall, resulting in a reduction of ANP synthesis and secretion from the atrial wall. Previous reports have demonstrated that the concentration of ANP in the right atrial appendages of human hearts is remarkably higher than that in the remainder of the atrial free wall. ${ }^{16}$ Furthermore, Omari and colleagues ${ }^{15}$ demonstrated that preservation of the right atrial appendage during elective coronary artery bypass operations improves reduced ANP secretion and reduced excretion of sodium after volume expansion. In the present study preservation of the right atrial appendage significantly lessens the decreased plasma ANP levels after the maze procedure. Taken together, these results suggest that right atrial appendectomy might be one of the causes of the reduced plasma ANP levels after the maze operation.

Examination of perioperative body fluid balance and the cumulative dose of dopamine administered during the first 7 days of the postoperative period showed that preservation of the atrial appendage increases the ability of the kidneys to excrete the fluid load after the operation. Perera and colleagues ${ }^{28}$ recently reported that the low-dose ANP infusion increased the urinary volume after bilateral atrial appendectomy in rats, although circulating ANP levels were not significantly increased, indicating that ANP can effectively induce diuresis after bilateral atrial appendectomy. These findings support our results that the ability of the kidneys to handle the fluid load was increased in the RAAX ${ }^{-}$ group, in which plasma ANP levels mildly increased after the maze operation. Dopamine decreases tubular
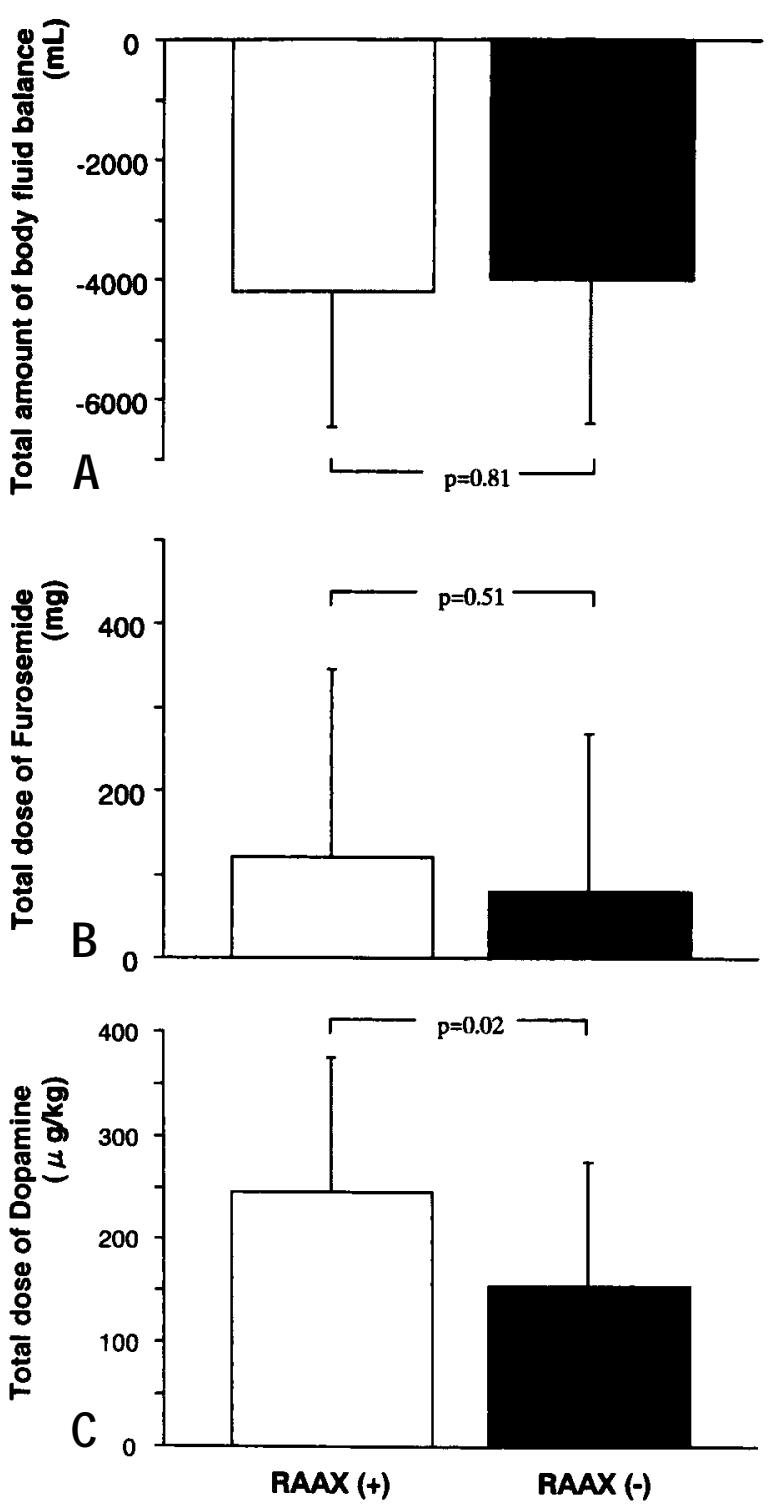

Fig 3. Bar graphs show the amount of body fluid balance (A) in the postoperative period and the total dose of furosemide (B) and dopamine (C) used in the same period in the $\mathrm{RAAX}^{+}$group (open columns) and the $\mathrm{RAAX}^{-}$group (closed columns).

sodium reabsorption caused by the inhibition of $\mathrm{Na} / \mathrm{K}$ adenosinetriphosphatase (ATPase) in renal tubules, resulting in an increase in natriuresis and diuresis. ${ }^{29}$ Furthermore, a recent report demonstrated that ANP also inhibits $\mathrm{Na} / \mathrm{K}$-ATPase in renal tubules. ${ }^{30}$ These results suggested that the natriuretic effects of these two substances might be due to the inhibition of $\mathrm{Na} / \mathrm{K}$ ATPase, which is a common pathway for regulation of natriuresis. Thus the improvement of the kidneys to handle the fluid load after the operation in the RAAX ${ }^{-}$ 
group might be due, in part, to the improvement of plasma ANP levels after the operation.

The restoration rate to sinus rhythm at 1 month after the operation in the $\mathrm{RAAX}^{-}$group was comparable with that in the $\mathrm{RAAX}^{+}$group in the present study. However, we cannot deny the possibility that the remaining right atrial appendage allows a macroreentrant circuit to develop, resulting in recurrence of atrial fibrillation. Thus further research is necessary to reveal whether the maze procedure with preservation of the right atrial appendage can maintain the sinus rhythm for a long period after the operation.

\section{Conclusion}

The present study has shown that preservation of the right atrial appendage lessens the reduction in plasma ANP levels after the maze procedure and that the increased plasma ANP levels may affect the ability of the kidneys to excrete the fluid load after the operation.

\section{REFERENCES}

1. Cox JL, Schuessler RB, D'Agostino HJ Jr, et al. The surgical treatment of atrial fibrillation. III. Development of a definitive surgical procedure. J Thorac Cardiovasc Surg 1991;101:569-83.

2. Cox JL, Boineau JP, Schuessler RB, et al. Successful surgical treatment of atrial fibrillation. JAMA 1991;266:1976-80.

3. McCarthy PM, Castle LW, Maloney JD, et al. Initial experience with the maze procedure for atrial fibrillation. J Thorac Cardiovasc Surg 1993;105:1077-87.

4. Cox JL, Boineau JP, Schuessler RB, Kater KM, Lappas DG. Five-year experience with the maze procedure for atrial fibrillation. Ann Thorac Surg 1993;56:814-23.

5. McCarthy PM, Cosgrove DM III, Castle LW, White RD, Klein AL. Combined treatment of mitral regurgitation and atrial fibrillation with valvuloplasty and the maze procedure. Am J Cardiol 1993;71:483-6.

6. Yoshihara F, Nishikimi T, Kosakai Y, et al. Atrial natriuretic peptide secretion and body fluid balance after bilateral atrial appendectomy by the maze procedure. J Thorac Cardiovasc Surg 1998;116:213-9.

7. Nakamura M, Niinuma H, Chiba M, et al. Effect of the maze procedure for atrial fibrillation on atrial and brain natriuretic peptide. Am J Cardiol 1997;79:966-70.

8. Veress AT, Sonnenberg H. Right atrial appendectomy reduces the renal response to acute hypervolemia in the rat. Am J Physiol 1984;247:R610-3.

9. Schwab TR, Edwards BS, Heublein DM, Burnett C Jr. Role of atrial natriuretic peptide in volume-expansion natriuresis. Am J Physiol 1986;251:R310-3.

10. Garcia R, Cantin M, Thibault G. Role of right and left atria in natriuresis and atrial natriuretic factor release during blood volume changes in the conscious rat. Circ Res 1987;61:99-106.

11. Stewart JM, Dean R, Brown M, et al. Bilateral atrial appendectomy abolishes increased plasma atrial natriuretic peptide release and blunts sodium and water excretion during volume loading in conscious dogs. Circ Res 1992;70:724-32.

12. Sakata M, Greenwald JE, Needleman P. Paradoxical relationship between atriopeptin plasma levels and diuresis-natriuresis induced by acute volume expansion. Proc Natl Acad Sci U S A 1988;85:3155-9.

13. Benjamin BA, Metzler CH, Peterson TV. Chronic atrial appendectomy alters sodium excretion in conscious monkeys. Am J Physiol 1988;254:R699-705.

14. Schwab TR, Edwards BS, Heublein DM, Burnett JC Jr. Role of atrial natriuretic peptide in volume-expansion natriuresis. Am J Physiol 1986;251:R310-3.

15. Omari BO, Nelson RJ, Robertson JM. Effect of right atrial appendectomy on the release of atrial natriuretic hormone. $\mathrm{J}$ Thorac Cardiovasc Surg 1991;102:272-9.

16. Rodeheffer RJ, Naruse M, Atkinson JB, et al. Molecular forms of atrial natriuretic factor in normal and failing human myocardium. Circulation 1993;88:364-71.

17. Kosakai Y, Kawaguchi AT, Isobe F, et al. Cox maze procedure for chronic atrial fibrillation associated with mitral valve disease. J Thorac Cardiovasc Surg 1994;108:1049-55.

18. Nishikimi T, Yoshihara F, Morimoto A, et al. Relationship between left ventricular geometry and natriuretic peptide levels in essential hypertension. Hypertension 1996;28:22-30.

19. Yoshihara F, Nishikimi T, Yoshitomi Y, et al. Left ventricular structural and functional characteristics in patients with renovascular hypertension, primary aldosteronism and essential hypertension. Am J Hypertens 1996;9:523-8.

20. Yoshitomi Y, Nishikimi T, Abe H, et al. Comparison of changes in cardiac structure after treatment in secondary hypertension. Hypertension 1996;27:319-23.

21. Hilberman M, Maseda J, Stinson EB, et al. The diuretic properties of dopamine in patients after open-heart operation. Anesthesiology 1984;61:489-94.

22. Duke GJ, Briedis JH, Weaver RA. Renal support in critically ill patients: Low-dose dopamine or low-dose dobutamine? Crit Care Med 1994;22:1919-25.

23. Davis RF, Lappas DG, Kirklin JK, Buckley MJ, Lowenstein E. Acute oliguria after cardiopulmonary bypass: renal functional improvement with low-dose dopamine infusion. Crit Care Med 1982;10:852-6.

24. Flancbaum L, Choban PS, Dasta JF. Quantitative effects of lowdose dopamine on urine output in oliguric surgical intensive care unit patients. Crit Care Med 1994;22:61-6.

25. Lindner A, Cutler RE, Goodman WG. Synergism of dopamine plus furosemide in preventing acute renal failure in the dog. Kidney Int 1979;16:158-66.

26. Lindner A. Synergism of dopamine and furosemide in diureticresistant, oliguric acute renal failure. Nephron 1983;33:121-6.

27. Kim KB, Lee CH, Kim CH, Cha YJ. Effect of the Cox maze procedure on the secretion of atrial natriuretic peptide. $J$ Thorac Cardiovasc Surg 1998;115:139-46.

28. Perera SA, Frame R, Brodman RF, Zeballos GA, Hintze TH, Panetta TF. Atrial natriuretic peptide replacement therapy in rats subjected to biatrial appendectomy. J Thorac Cardiovasc Surg 1995;109:976-80.

29. Takemoto F, Cohen HT, Satoh T, Katz AI. Dopamine inhibits $\mathrm{Na} / \mathrm{K}$-ATPase in single tubules and cultured cells from distal nephron. Pflugers Arch 1992;421:302-6.

30. Aperia A, Holtback U, Syren ML, Svensson LB, Fryckstedt J, Greengard P. Activation/deactivation of renal Na+,K(+)-ATPase: a final common pathway for regulation of natriuresis. FASEB $\mathrm{J}$ 1994;8:436-9. 